\title{
GCU
}

Glasgow Caledonian

University

University for the Common Good

\section{Load capacity probabilistic sensitivity analysis of thin-walled beams}

Kotelko, Maria; Lis, Pawel; Macdonald, Martin

Published in:

Thin-Walled Structures

DOI:

10.1016/j.tws.2017.02.007

Publication date:

2017

Document Version

Author accepted manuscript

Link to publication in ResearchOnline

Citation for published version (Harvard):

Kotelko, M, Lis, P \& Macdonald, M 2017, 'Load capacity probabilistic sensitivity analysis of thin-walled beams', Thin-Walled Structures, vol. 115, pp. 142-153. https://doi.org/10.1016/j.tws.2017.02.007

\section{General rights}

Copyright and moral rights for the publications made accessible in the public portal are retained by the authors and/or other copyright owners and it is a condition of accessing publications that users recognise and abide by the legal requirements associated with these rights.

Take down policy

If you believe that this document breaches copyright please view our takedown policy at https://edshare.gcu.ac.uk/id/eprint/5179 for details of how to contact us. 


\title{
Load Capacity Probabilistic Sensitivity Analysis of Thin-Walled Beams
}

\author{
Maria Kotelko ${ }^{*}$, Pawel Lis ${ }^{1}$, Martin Macdonald ${ }^{2}$ \\ ${ }^{1}$ Łódź University of Technology, Department of Strength of Materials, \\ Łódź, Poland \\ ${ }^{2}$ Glasgow Caledonian University, School of Engineering \& Built Environment, \\ Glasgow, Scotland
}

$(*)$ Corresponding author:

maria.kotelko@p.lodz.pl

\begin{abstract}
The paper deals with the load carrying capacity probabilistic variance-based sensitivity analysis of thin-walled box-section girders subjected to pure bending. The lower- and upper-bound load capacity estimation is performed using two different analytical methods. The sensitivity analysis performed is based on the methodology of the Monte-Carlo method. The analysis is carried out using the polynomial decomposition and multi-dimensional linear regression. The sample results obtained are presented in diagrams and pie charts showing the sensitivity of load capacity to different random input variables (material properties and geometrical parameters). The variance-based analysis (Anova) of lower-bound and upper-bound load capacity estimation is carried out, from which some conclusions are derived, if (and how) assumed changes in standard deviations of input variables influence the magnitude of the load capacity and differences in upper-bound and lower-bound load capacity estimations. The results of Anova tests are shown in sample histograms. Some final conclusions concerning the efficiency of the applied models and the statistically significant influence of input random variables (yield stress, wall thickness, height and length of the beam) upon the upper-bound and lower bound estimation of the load capacity as well as the difference of these two estimations, are presented.
\end{abstract}

Keywords: thin-walled girders, bending, load-capacity, sensitivity analysis. 


\section{Highlights:}

- Load-carrying capacity probabilistic sensitivity analysis of steel box-section beams subjected to pure bending is carried out and is concerned with the upper-bound and lower-bound estimation of load-carrying capacity.

- Input random quantities are geometrical parameters of the beam and material properties.

- The analysis of variance (ANOVA) is performed, which allows not only the determination of the influence of random input variables upon the variance of output quantities, but also to conclude if (and how) random input variables influence the magnitudes of output quantities themselves.

- The efficiency of a statistically significant empirical multi-dimensional model for the lower-bound estimation in terms of considered input random quantities is weak.

- The upper-bound estimation induction (influence on the variance) is generated mainly by the yield stress.

- Influence upon the magnitude of the upper-bound load capacity estimation is induced by the standard deviation of wall thickness only. Thus, a tolerance of the wall thickness (of metal sheet thickness) is of crucial importance.

- The difference between two load capacity estimations (upper-bound and lower-bound) is statistically influenced only by the standard deviation of the yield stress.

\section{Introduction}

The load carrying capacity of thin-walled structures (TWS) is influenced by a number of material and geometrical parameters, which can be of random character. Thus, the application of sensitivity and uncertainty analysis is of use in the evaluation of the influence of variability of different geometrical and material imperfections on the variability of the load carrying capacity of TWS.

The random character of material parameters comes not only from the manufacturing process of metal sheets, but in the case of cold formed thin walled members, from the 
forming process (e.g. cold rolling). Material properties are sometimes substantially different from those of the steel, strip, plate or bar before forming. The reason for this is that the cold forming operation increases the yield and tensile strengths, and at the same time decreases the ductility (Kankanamge and Mahendran 2011 [1]; Macdonald, Rhodes and Taylor 2000 [2]; Chen and Young 2004 [3]). This behaviour is highlighted in Figure 1.

Fig. 1: Variation in predicted average yield strength for a cold-formed bend with variation in geometry ([2]).

The mechanical properties are also different in various parts of the cross-section. This is due to the increase in the yield strength and the tensile strength of the material in the corners of the section which are considerably higher than the material in the flat elements (Karren and Winter [4]). Reasons for geometrical imperfections may be different: manufacturing process of TWS members, welding process, etc.

Sensitivity analysis methods are of two types: deterministic and stochastic (probabilistic). The deterministic sensitivity analysis, which may be referred to as a parametric study, is widely used in structural design. However, using this approach does not always obtain an answer about the sensitivity or uncertainty of output parameters in terms of input data. Using the probabilistic sensitivity analysis, the input parameters that have a predominant influence on the uncertainty of the output variables (e.g. load capacity) can be determined.

In recent years the deterministic approach to the design of TWS has often been replaced by the probabilistic one. It particularly concerns thin-walled girders. Also, some new design codes, particularly concerning TWS in civil engineering, treat the structural reliability and load carrying capacity of TWS as a probabilistic problem. However, in using any probabilistic method, a great number of calculations have to be performed, and the main limitation becomes the time of computation, which depends on the method applied.

As far as an applied calculation apparatus is concerned, methods of probabilistic sensitivity analysis can be divided into two groups: analytical or analytical-numerical 
methods and "purely" numerical methods, mainly the Finite Element Method (FEM) [47].

The strength of thin-walled structures is usually calculated on the basis of the "effective width" model and the ultimate capacity is evaluated using a reduced or effective cross-section and, additionally, the elastic limit for maximum stress. This approach is currently used in almost all design codes and leads to the lower-bound estimation of the load-carrying capacity. The elastic post-buckling behaviour of a thin-walled beam was analysed by Kolakowski et al [5], who solved the problem using the asymptotic method in the range of the second order approximation. The algorithm based on the asymptotic method is relatively simple and delivers the lowerbound estimation of the load-carrying capacity in a shorter computation time.

However, TWS members display a significant post-elastic capacity. This means that the actual load carrying capacity of any thin-walled member is higher than the ultimate load calculated using the method mentioned above.

Thus, the alternative approach is the upper-bound estimation of the load carrying capacity, consisting of the determination of the intersection point of a post-buckling path, evaluated using either analytical or numerical method, and a rigid-plastic failure curve obtained from the plastic mechanism analysis (Kotełko et al. [6,7]).

The present paper deals with the sensitivity analysis of the load carrying capacity of a thin-walled, box-section beam subjected to pure bending as shown in Figure 2 . The sensitivity analysis is performed both for lower-bound and upper-bound estimation of the load carrying capacity. Two analytical-numerical methods are applied to calculate the lower-bound and upper-bound load carrying capacity of the beam.

Fig. 2: Box-section girder under pure bending: (a) dimensions; (b) load and support lay-out. 


\section{State of the art of the subject}

First attempts to apply a probabilistic approach to sensitivity analysis go back to the 1970s. One of the pioneering papers was published by Fukumoto et al. in 1976 [8], as well as Arorra $(1992[9,10])$. In Poland, the pioneers in this area were Mróz (1983 [11,12]), Szymczak (1991 [13,14]) and Szefer (1983 [15]). Mróz [11] and Szefer [15] applied the probabilistic approach to the sensitivity analysis of non-linear mechanical systems.

In the $1980 \mathrm{~s}$, the first results of research into the application of the probabilistic approach to the analysis of stability of structures were published. In Poland, Murzewski [16] analysed the problem of random instability of high structures (building structures and cranes). The random variables were the dead weight of the structures and wind force. He also applied the probabilistic approach to the problem of conjunction of two independent random events, i.e. elastic buckling and plastic failure of axially compressed columns [17]. The same approach was continued in other research work concerning elastic-plastic buckling of frames with imperfections (Murzewski [18]). In [13,14] the sensitivity analysis of load-capacity of I- beams subjected to torsion was analysed, while in [20] a similar problem concerning beams of bi-symmetrical cross-section was considered. A detailed discussion of problems related to sensitivity analysis of beams and frames was published in [1] and by Szymczak in [19], as well as in [21] and [22].

The probabilistic sensitivity analysis in the domain of thin-walled structures was up until now applied to the estimation of load capacity of beam-columns of I-section mainly. Some analyses have been performed for columns in compression.

Z. and J. Kala [25] applied the probabilistic sensitivity analysis to the buckling and limit load analysis of I-section columns under compression, taking into account the variance change of initial geometric imperfection. The analysis is based on the Sobol method. Puklicky and Kala [23] performed the sensitivity analysis into limit states and load capacity of composite I-section columns (filled with concrete) used in building engineering. Long columns and global buckling of columns was considered. FE simulations and LHS method (Latin Hypercube Distribution) were applied. The random variables were both material parameters and geometrical imperfections. They 
stated that the results of the sensitivity analysis, which took into account the load capacity redundancy in the post-elastic state, can be used in load-carrying capacity calculation, including standard recommendations.

The fundamental works in the domain of the sensitivity analysis of beams were published by Z.Kala, J.Kala, Skaloud and Melcher [23-37].

Szymczak [19] performed first-order sensitivity analysis based on the variational approach. The subjects of this analysis were thin-walled beams of bi-symmetric crosssection, subjected to combined load (bending, compression and torsion). Analysis has been extended onto thin-walled frames under torsion. In [21], Szymczak et al. presented the review of sensitivity analysis solutions based on the variational approach, concerning thin-walled beams of mono- and bi-symmetrical cross-sections, subjected to combined loading. The output variables were deflections of beams, sectional forces, as well as modes and frequencies of torsional vibrations.

Kala, Skaloud et al. [26] carried out a sensitivity analysis of I-section beam load capacity in the pre-buckling state were they used the FE method. The random variables were material parameters and wall thickness. They did not state any influence of input random variables on the load capacity itself (whether it increases or decreases) and they did not determine a confidence level. Kala et al. analysed in $[31,32,34,35]$ the influence of initial deflection of I-section beam walls on their load carrying capacity, using the probabilistic approach. In [32] a model of the beam subjected to bending was presented, which took into account the influence of spot welds upon initial geometrical imperfections. In [34], the influence of initial geometrical imperfections of the beam consisting of plate members, coming from welding process, was analysed with the application of the LHS method and the results were partially validated with experiments. The influence of geometrical and material parameters, treated as random variables, on the load capacity of I-section beams of varying wall slenderness was presented in [36]. The authors stated that the load capacity was more sensitive to the wall thickness variance than to the wall width variance.

In all papers presented above the same method consisting of the generation of independent random variables was applied. However, none of those papers determined the qualitative influence of these variables on the load capacity itself 
(from the statistical point of view), accounting for the confidence level of performed statistical tests.

In this paper, simple algorithms describing the load carrying capacity of thinwalled box-section beams have been derived using the method of multi-dimensional linear regression. This enabled the determination of the statistical significance of multi-dimensional models of upper- and lower-bound load capacity estimation in terms of analysed input random variables, as well as to search for trends of change of both estimations, and any difference between them in terms of standard deviations of input quantities. Investigation into these trends and an estimation of statistical efficiency of applied models are new factors which have not been investigated so far.

\section{Load carrying capacity computational models}

\subsection{Subject of the analysis}

The subject of investigation was a segment of a thin-walled, box section girder, situated between two adjacent diaphragms as shown in Figure 2 above. It is assumed that the bending moment acts in the plane created by the axis of the cross-section symmetry and the longitudinal axis of the beam. The assumed model of loading (pure bending between two adjacent diaphragms) can be treated as a computational model of the beam segment, which is situated far enough away from supports so that any shear effect can be neglected. It was also assumed that failure of the beam is initiated by buckling of the flange subject to compression, and that the first yield is assumed to occur in the compressed flange so that the plastic flange mechanism is expected to occur $[6,7]$. Thus, the failure analysis, based on the yield line approach, was carried out using the theoretical model of plastic mechanism as shown in Figure 3. The mechanism model was originally developed by Kecman [38] and modified by Kotelko [6]. It was also confirmed experimentally by many other researchers $[39,42]$. 
Fig. 3: Plastic mechanism of failure in box-section beam under pure bending: (a) theoretical model [6]; (b) experiment [39,42].

\subsection{Computational model}

The load-carrying capacity of the girder was calculated using the software code 'NOSNOSC' elaborated by Kołakowski, Kotełko and Kubiak [43]. The code provides information about the girder's structural behaviour in over the full range of loading (up to and beyond the ultimate load) and calculates the lower bound and upper-bound load carrying capacity estimations (denoted below as OD and OG respectively abbreviations come from Polish research). OD (lower-bound) corresponds to the first yield in the beam's compressed flange, while OG (upper-bound) is calculated as an ordinate of the inter-section of the post-buckling elastic path with the failure path (Figure 4).

The post-buckling elastic path is determined using the asymptotic method based on the Koiter asymptotic approach and using analytical-numerical method (ANM algorithm) elaborated by Kołakowski et al. [41,44]. Namely, the non-linear problem is solved by Byskov and Hutchinson's asymptotic approach. The displacement fields $\overline{\mathbf{U}}$, and the sectional force fields $\overline{\mathbf{N}}$, are expanded into a power series in the buckling mode amplitudes $\zeta_{\mathrm{j}}\left(\zeta_{\mathrm{j}}\right.$ is the amplitude of the $\mathrm{j}$-th buckling mode divided by thickness of the first component plate, $\left.\mathrm{h}_{1}\right)$ :

$$
\begin{aligned}
& \overline{\mathbf{U}}=\lambda \bar{U}_{i}^{(0)}+\zeta_{j} \bar{U}_{i}^{(j)}+\zeta_{j} \zeta_{k} \bar{U}_{i}^{(j k)}+\ldots \\
& \overline{\mathbf{N}}=\lambda \bar{N}_{i}^{(0)}+\zeta_{j} \bar{N}_{i}^{(j)}+\zeta_{j} \zeta_{k} \bar{N}_{i}^{(j k)}+\ldots
\end{aligned}
$$

The ANM algorithm calculating the post-buckling elastic path is based on the numerical method of the transition matrix using Godunov's orthogonalisation.

In order to determine maximum stresses in the girders' plate members under compression, the width of a compressed flange is reduced to the effective width to obtain the real decrease in flexural stiffness of the cross-section after local buckling. The first yield threshold criterion is used in order to estimate the load capacity of the girder (lower-bound estimation OD) (Maniewicz, Kołakowski [5,41]). 
The failure path is derived from the yield-line analysis, based on the plastic mechanism theoretical model, shown in Figure 3. The energy method is applied in order to calculate an actual bending moment at the global plastic hinge [6,7]. Starting from the principle of virtual velocities, the total energy of plastic deformation, dissipated during rotation about the angle $\theta$ of two parts of the girder at the global plastic hinge, takes the following form:

$$
\begin{aligned}
& W(\theta)=\sum_{i} l_{i} \int_{0}^{\beta_{i}} m_{p \beta}^{i} d \beta+\sum_{j} \Gamma_{j}\left(m_{p \beta}^{j}, \rho_{0 j}, \bar{z}_{j}, \beta_{j}\right)+ \\
& \sum_{k} \Omega_{k}\left(m_{p \beta}^{k}, \rho_{0 k}, \bar{z}_{k}, \lambda_{k}, \beta_{k}\right)
\end{aligned}
$$

A length of any yield line $1_{j}$, as well as angles $\beta_{j}$ of rotation of two adjacent walls of the global plastic hinge along a stationary yield line, and all other functional parameters of $\Gamma_{\mathrm{k}}$ and $\Omega_{1}$, corresponding to the energy dissipated at local plastic corners and travelling yield line respectively, have to be expressed in terms of the angle $\theta[6]$. The total energy of plastic deformation (2) is calculated using a numerical procedure, by means of the incremental method - for subsequent increments of the angle $\Delta \theta$ which correspond to the increments of $\Delta \beta$.

A bending moment at the global plastic hinge is calculated using a numerical differentiation procedure of the energy with respect to the angle $\theta$. A curve representing the bending moment capacity at collapse in terms of the rotation angle $\theta$ at the global plastic hinge is referred to as a failure path. An ordinate of the intersection point of the latter and the post-buckling loading path (obtained from ANM algorithm) is acknowledged as the upper-bound load-carrying capacity (OG).

The output quantities obtained from the code "NOSNOSC" are the lower-bound (OD) and upper-bound (OG) maximum bending moments of the girder.

The exemplary chart obtained from the program 'NOSNOSC' is shown in Figure 5. The abscissa represents the angle of rotation at the global plastic hinge (angle of deflection in the elastic range) normalised with respect to the buckling (critical) angle. The ordinate is the normalised bending moment with respect to the buckling one. The OD (circular point) and OG (inter-section of post-buckling path and failure path) ordinates are indicated. 
Fig. 4: Exemplary chart of program 'NOSNOSC'.

\section{Probabilistic sensitivity analysis}

\subsection{Methodology}

The sensitivity analysis was performed to determine the sensitivity of OD and OG with respect to the variance of several random input quantities, i.e. material parameters (Young's modulus, Poisson's ratio and yield stress) and dimensions of the beam. The initial geometrical imperfections were not taken into account.

The material parameters and their standard deviations are taken from a publication by Melcher et al. [30,37]. Kala and Melcher [30,45] carried out a comprehensive statistical analysis of material parameters of steel produced in the Czech Republic. The tests were performed for plates made from steel S235. In the present sensitivity analysis the probabilistic distribution, mean values and standard deviations of Young's modulus, Poisson's ratio and yield stress were taken from publication [30]. An exemplary histogram for yield stress is shown in Figure 5.

Fig. 5 : Histogram of the yield stress distribution [30].

A wall thickness $\mathrm{H}=1 \mathrm{~mm}\left(\mathrm{H}_{\mathrm{A}}=\mathrm{H}_{\mathrm{B}}=\mathrm{H}\right)$ was used in the analysis. The dimensions of the beam assumed in the analysis fulfill the proportions (width-toheight and width-to-thickness ratios), which are used and recommended for steel boxsection girders, e.g. of overhead cranes. Design code EN 1993-1-3:2006 does not define tolerances of dimensions for thin-walled steel structures. Polish and European codes for metal products PN-EN 10051 defines the tolerance for plate thickness 1 $\mathrm{mm}$, which amounts to $\pm 0.13 \mathrm{~mm}$. The sensitivity analysis was carried out for this range of tolerance and beyond. An exemplary histogram for wall thickness is shown in Figure 6. 
Fig. 6 : Histogram of wall thickness distribution.

The input random quantities are indicated in Table 1 (see notation in Figure 2).

Table 1: Input random variables

${ }^{(*)}$ L (Figure $\left.2 b\right)$ - distance between diaphragms

The methodology based on the Monte Carlo method (Szymczak, [21]) is applied in the analysis. The analysis consists of the polynomial decomposition carried out using multi-dimensional linear regression. The calculations were performed using the program Minitab 15 [46]. Knowing the distribution of input variables, it is possible using the Monte-Carlo method, to generate adequate data files [44]. After generating the data files, the values of output variables have to be determined, using the code "NOSNOSC", and then, after generating input files, the equations of regression were derived, performing the decomposition to polynomial through linear regression:

$$
y=a_{1} x_{1}+a_{2} x_{2}+\ldots+a_{m} x_{n}+b i a
$$

where, bias is a coefficient stabilising a regression model, (enhancing the computational model in order to decrease a prognosis error). In the next step, polynomial component variances are calculated as follows:

$$
s_{1}=V_{1}\left(a_{1} x_{1}\right), s_{2}=V_{2}\left(a_{2} x_{2}\right), \ldots s_{m}=V_{m}\left(a_{m} x_{m}\right)
$$

After performing the analysis of variance of particular variables multiplied by direction coefficients of regression, one can determine the significance of each variable and its contribution to the final value of a predicted quantity. After calculating the sensitivity breakdown (relation of individual variance to the total value):

$$
W_{i}=\frac{V i}{\sum_{i=1}^{n} S_{i}}
$$


the sensitivity coefficients and the influence of input random variables upon the out variables were determined.

Because linear regression (3) was applied, first order sensitivity coefficients were calculated. Thus, within the sensitivity analysis, additive (main) effects have been studied.

Within the framework of each run of the Monte Carlo method, the OD and OG values were found using the code 'NOSNOSC'. For each calculation case, 100 Monte Carlo simulation runs were conducted. After performing iterations, the procedure of multi-dimensional linear regression was carried out. Data were generated on the basis of normal Gauss distribution, described by the parametric function (6),

$$
f(x)=\frac{1}{\sigma \sqrt{2 \pi}} e^{-\frac{(x-m)^{2}}{2 \sigma^{2}}}
$$

The „6 $6 \sigma$ routine has been applied. All calculations were performed on the $95 \%$ significance level and the scheme of the computational procedure is shown in Figure 7.

Fig. 7: Sensitivity analysis flowchart.

\subsection{Results}

On the basis of the regression analysis the following preliminary conclusions were derived: a statistically significant empirical multi-dimensional model exists for the lower-bound estimation (OD) in terms of considered input random quantities. However, its efficiency is weak. Based on the least squares method, the model produced a $25 \%$ error. On the contrary, the efficiency of an analogous empirical model for the upper-bound estimation (OG) was high (above 98\%). Thus, further sensitivity analysis was focused on the upper-bound load-capacity estimation (OG). Sample results of this analysis are shown below. Figure 8 shows the results of the 
sensitivity analysis of OG in terms of the variance of wall thickness $H$ represented by pie charts and breakdown coefficient diagram.

On the basis of the results of wall thickness standard deviation change (thickness tolerance), it can be concluded that the OG induction is generated mainly by the yield stress $(60 \%)$, when the tolerance of thickness is restricted (here $1 \mathrm{~mm} \pm 0.01$ ). Increment of the thickness tolerance changes this structure.

Fig. 8: Sample pie charts OG sensitivity analysis - wall thickness variance: (a) 1\% standard deviation; (b) 2\% standard deviation; (c) diagram of breakdown coefficients.

Fig. 9: Pie chart of OG sensitivity analysis in terms of beam height variance: (a) SD 0.5 ; (b) SD. $0.6[\mathrm{~mm}]$.

The sensitivity analysis was also performed for the girder's height variance, with the standard deviation shown in Table 1. The results of the regression analysis and sensitivity analysis in terms of height variance are shown in Figure 10.

Analogous results for the analysis in terms of dimension L (distance between diaphragms) are shown in Figure 10.

Fig. 10: Pie chart of OG sensitivity analysis in terms of distance L variance: (a) SD 0.5; (b) SD 0.6 ; (c) SD 0.7 [mm].

The analysis was also carried out in terms of the variance of the yield stress $R_{e}$, with the standard deviations shown in Table 1. The results of the regression analysis and sensitivity analysis in terms of the yield stress variance are shown in pie charts in Figure 11. The corresponding diagram is shown in Figure 12. The analysis indicates that the larger the standard deviation of Re is, the higher the influence of this quantity is on OG. It varies linearly from $47.5 \%$ up to about $70 \%$. The increase of the Re influence is associated with a decrease of the influence of other material output quantities like Young's modulus and Poisson's ratio (both of linear character). Influence of geometrical parameters (dimensions) is approximately constant. 
Fig. 11: Sample pie charts (OG sensitivity analysis - yield stress variance): (a) $21.5 \mathrm{MPa}$ $\mathrm{SD}$; (b) $23.5 \mathrm{MPa}$ SD.

Fig. 12: Results of OG sensitivity analysis - yield stress variance.

\section{Variance-based analysis of upper- and lower-bound estimation of beam load capacity}

The sensitivity analysis allows one to determine not only an influence of variance of random input variables upon the variance of output quantities, but also to conclude if (and how) assumed changes in standard deviations of input variables influence the magnitude of load capacity and differences in upper-bound (OG) and lower-bound (OD) estimations.

Using the test ANOVA (Analysis Of Variance), a comparison of influence of standard deviations of yield stress, wall thickness, and also, height and length of the beam segment on the upper (OG)- and lower-bound (OD) estimation of the load carrying capacity on the requested (95\%) confidence level was carried out. Also, the influence of change in standard deviations of input variables (parameters) on the difference between OG and OD was determined.

This analysis was based on results from four tests. In the first test, the statistical influence of standard deviations of input random quantities on the magnitude of lower-bound load capacity estimation (OG) was checked. In the second test, the corresponding influence on the magnitude of upper-bound load capacity estimation (OG) was investigated. In the third test, the statistical influence of standard deviations of random variables upon the OD-OG difference was checked. Finally, the last test was concerned with the statistical influence of input random variables on the probability that OG and OD values are the same.

All data files were checked to see if they were of normal distribution (on the $95 \%$ confidence level). For the data files generated within the sensitivity analysis, the ANOVA tests were carried out using the numerical code MINITAB15 [46]. Sample histograms of OG-OD differences for the variance of selected input variables are shown in subsequent figures. 
Figure 13 presents the histogram of OD-OG differences in terms of wall thickness variance. Figures 14 and 15 show similar histograms for height beam variance and yield stress variance, respectively.

The deviation of thickness does not generate any distinction of samples (based on means of difference between OG and OD) as a different sample material on the requested (as a standard 95\%) confidence level.

The increase of the yield stress standard deviation induces an increase in the differences of OG and OD (see the "shift" of the histogram in Figure 15). Also, a "shift" means that the differences are noticed. A similar but weaker phenomenon is observed in the case of the beam height (see Figure 14), and, on the contrary, this is not observed for the wall thickness variance (Figure 13). The distribution of OG-OD differences is not normal for the 95\% confidence level (Figure 14) in the case of the yield stress variance and height variance, while for the wall thickness variance at the same confidence level this distribution is normal (Figure 12). The same concerns the beam's length L.

Fig. 13: Sample histogram - upper-bound (OG) and lower-bound (OD) differences for wall thickness variance.

Fig. 14: Sample histogram - upper-bound (OG) and lower-bound (OD) differences for beam height variance.

Fig. 15: Sample histogram - upper-bound (OG) and lower-bound (OD) differences for the yield stress variance.

The summary of ANOVA tests results is shown in Table 2.

Table 2: Summary of ANOVA tests results.

The "+" sign indicates that a statistically significant (on the $95 \%$ confidence level) influence of an analysed variable exists, the "-." sign indicates that such an influence does not exist. 
Conclusions of this summary are as follows:

- Statistically significant (on a 95\% confidence level) influence upon the magnitude of the lower-bound load capacity estimation (OD) is exerted only by the standard deviation of the yield stress.

- Statistically significant (on a 95\% confidence level) influence upon the magnitude of the upper-bound load capacity estimation (OG) is induced by the standard deviation of wall thickness only.

- The difference OD-OG between two load capacity estimations is statistically influenced only by the standard deviation of the yield stress.

\section{Final remarks}

Results of the sensitivity analysis performed show how the quality of structural steel and imperfections of geometrical parameters (tolerance change of these parameters) affect the sensitivity of the load carrying capacity of the beam.

As was mentioned, the efficiency of a statistically significant empirical multidimensional model for the lower-bound estimation (OD) in terms of considered input random quantities is weak. Thus, the sensitivity analysis was mainly focused on the upper-bound estimation (OG). The upper-bound estimation (OG) induction is generated mainly by the yield stress. Activity of the yield stress is reduced with the tolerance change of wall thickness, but is elevated by the increase of the yield stress standard deviation itself. The tolerance change of the height B and length L do not influence the activity of the yield stress.

The analysis of variance (ANOVA tests) allowed the authors to conclude how the standard deviations of input random variables influence statistically the change in magnitude of upper-bound (OG), lower-bound (OD) and difference (OG-OD) estimations of the load capacity of the beam.

The results of four-step tests, described above, allow for the conclusion that statistically significant (on the assumed confidence level) influence upon the magnitude of the lower-bound load capacity estimation (OD) is exerted only by the standard deviation of the yield stress, and standard deviations of geometrical dimensions do not influence this estimation. 
On the contrary, statistically significant (on the assumed confidence level) influence upon the magnitude of the upper-bound load capacity estimation (OG) is induced by the standard deviation of wall thickness only. Neither the standard deviation of the yield stress, nor other geometrical parameters (height and length) do not influence this estimation. Thus, a tolerance of the wall thickness (of metal sheet thickness) is of crucial importance.

One of the most important conclusions is that the difference OD-OG between two load capacity estimations is statistically influenced only by the standard deviation of the yield stress. Thus, the analysis performed allows for the conclusion that a "redundancy" of the load capacity of the beam (the post-elastic capacity) is more sensitive to the yield stress deviation than to the wall thickness deviation and deviations of other geometrical parameters (height and length).

The results presented in the paper are based on linear models of analysis without interactions. The relations between indicators of OG and OD were also checked with the use of non-linear models. However, the improvement of the estimation efficiency of those models was about $4 \%$.

\section{References}

1. Kankanamge, N.D. and M. Mahendran. 2011. Mechanical Properties of ColdFormed Steels at Elevated Temperatures. Thin-Walled Structures [online]. Vol. 49(1), [Accessed 23 May 2011], pp.26-44. Available from: http://dx.doi.org/10.1016/j.tws. 2010.08.004.

2. Macdonald, M., Rhodes, J., and Taylor, G.T. 2000. Mechanical Properties of Stainless Steel Lipped Channels. In: Fifteenth International Specialty Conference on Cold-Formed Steel Structures, 19-20 October 2000, St.Louis, USA, Rolla, MO 65401: University of Missouri-Rolla.

3. Chen, J. and Young, B. 2004. Mechanical Properties of Cold-Formed Steel at Elevated Temperatures. In: Seventeenth International Specialty Conference on Cold-Formed Steel Structures, 4-5 November 2004, St. Louis, USA, Rolla, MO 65401: University of Missouri-Rolla. 
4. Karren,K.W. And Winter,G., "Effects of Cold-Forming on Light-Gage Steel Members”. Proc. ASCE J.Struct.Div.,Vol.93(ST1), pp.433-469. February 1967.

5. Manevich, A.. and Kołakowski, Z. 1996. Influence of local post-buckling behaviour on bending of thin-walled beams, Thin-Walled Structures, Vol. 25, No 3, pp. 219-230.

6. Kotełko, M. 2004. "Load-capacity estimation and collapse analysis of thinwalled beams and columns - recent advances." Special Issue - Cold formed steel structures: recent research advances in Central and Eastern Europe, Ed.by D. Dubina, Thin-Walled Structures V.42/2, Elsevier 2004, 153-175.

7. Kotełko, M. 2011. Load-capacity and mechanisms of failure of thin-walled structures (in Polish - Nośność i mechanizmy zniszczenia konstrukcji cienkościennych), WNT, Warszawa, Poland.

8. Fukumoto, Y.; Kajita, N. and Aoki, T. 1976. Evaluation of Column Curves Based on Probabilistic Concept, in Proc. of Int. Conference on Stability, Prelim. Rep., publ. by Gakujutsu.

9. Arorra J. S. and Haug E. J., Methods of design sensitivity analysis in structural optimization. AIAA J. 17,970-973, 1979.

10. Arorra J. S. and Cardoso J. B. 1992. Variational principle for shape design sensitivity analysis, AIAA, Journal, 30, 2, 538-547.

11. Dems, K., and Mróz, Z. 1983. Variational approach by means of adjoins system to structural optimization and sensitivity analysis I variation of material parameters within fixed domain, Int. Journal of Solids and Structures, 19, 8, 677-692.

12. Haftka, R.T. and Mróz, Z. 1986. First and second-order sensitivity analysis of linear and nonlinear structures, AIAA Journal 24, 7, 1187-1192.

13. Budkowska, B.B. and Szymczak, C. 1991. Sensitivity analysis of thin-walled Ibeams undergoing torsion, Thin-Walled Structures Vol.12, 51-61.

14. Budkowska, B.B. and Szymczak, C. 1992. Sensitivity analysis of critical torsional buckling load of thin walled I-columns resting on elastic foundation, Thin-Walled Structures Vol.14, 37-44.

15. Szefer, G. 1983. Optimization and sensitivity analysis of dynamic systems with distributed parameters (in Polish) Mechanika, 1, 4, 5-36. 
16. Murzewski, J. 1988. Random instability of structure's position (in Polish) Proc. of $5^{\text {th }}$ Stability of Structures Symposium - Cedzyna, Poland, pp. 87-90.

17. Murzewski, J. 1994. Elasto-plastic stability of steel frames with imperfections (in Polish), Proc. of $7^{\text {th }}$ Stability of Structures Symposium - Bielsko-Biała, Poland, pp 113-118.

18. Murzewski, J. 1977. Joint probability of elastic and plastic instability modes, Regional Colloquium on Stability of Steel Structures, Budapest, Final Reports, pp. 249-268.

19. Szymczak, C. 2003. Sensitivity analysis of thin-walled members, problems and applications, Thin Walled Structures 41, 271-290.

20. Iwicki P., Problems of sensitivity analysis of thin-walled bars of bi-symmetrical open cross-section under static load (in Polish: Problemy analizy wrażliwości prętów cienkościennych o przekroju bisymetrycznym otwartym poddanych działaniu obciażeń statycznych. $\mathrm{PhD}$ thesis . Gdańsk University of Technology, 1997.

21. Szymczak C., Kreja I., Mikulski T., Kujawa M.: Sensitivity analysis of beams and frames made of thin-walled members. Gdańsk University of Technology, 2003.

22. Kreja I.and Szymczak C., Numerical simulation of a thin-walled beam with warping stiffeners undergoing torsion, TASK Quarterly, 6, 453-460, 2002.

23. Z. Kala, L. Puklicky, A. Omishore and M. Karmazinova, J. Melcher Stability problems of steel-concrete members composed of high-strength materials Journal of Civil Engineering and Management 16(3):352-362 2010.

24. Kala, Z., Fuzzy probability analysis of the fatigue resistance of steel structural members under bending, Journal of Civil Engineering and Management 14(1): 67-72. doi:10.3846/1392-3730.2008.14.67-72. 2008.

25. Kala, Z., Sensitivity assessment of steel members under compression, Engineering Structures 31(6): 1344-1348. oi:10.1016/j.engstruct.2008.04.001 2009.

26. Kala, Z.; Kala, J.; Škaloud, M. and Teplý, B., Analysis of the Effect of Initial Curvature on the Stress State in Breathing Webs, in Proc. of International Colloquium, Budapest, 425-432. ISBN 96305795022002. 
27. Kala, Z.; Kala, J.; Škaloud, M. and Teplý, B., Sensitivity Analysis of the Stress State in the Crack-Prone Areas of Breathing Webs, in Proc. of 20th Czech and Slovak Conference "Steel Structures and Bridges”, Prague, 641-646. ISBN 8001-02747-3. 2003.

28. Kala, Z.; Kala, J. and Teplý, B., Effect of Technological Imperfections on the Bearing Capacity of Steel Members, Roczniky Inzynierii: 71-80. ISSN 15058425. 2002.

29. Maquoi, R. and Škaloud, M., Some Remarks in Regard to the Fatigue Analysis of Steel Plate Girders with Breathing Webs, in Proc. of 20th Czech and Slovak Conference"Steel Structures and Bridges”, Prague, 397-402. ISBN 80-0102747-3. 2003.

30. Melcher, J.; Kala, Z.; Holický, M.; Fajkus, and M.; Rozlívka, L., Design characteristics of structural steels based on statistical analysis of metallurgical products, Journal of Construction Steel Research 60(3-5): 795808.doi:10.1016/S0143-974X(03)00144-5. 2004.

31. Melcher, J.; Škaloud, M.; Kala, Z. and Karmazínová, M., Sensitivity and statistical analysis within the elaboration of steel plated girder resistance, Advanced Steel Construction5(2): 120-126. 2009.

32. Z. Kala, J. Kala, J. Melcher, M. Skaloud and A. Omishore, Imperfections in steel plated structures - should we straighten their plate elements. NSCC2009 552-555.

33. Kala Z. and Kala J., Variance-Based Sensitivity Analysis of Stability Problems of Steel Structures using Shell Finite Elements and Nonlinear Computation Methods, Department of Structural Mechanics Brno University of Technology, Faculty of Civil Engineering Veveří p. 95, Brno.

34. Z. Kala, J. Kala, J. Melcher, and M. Škaloud., The influence of thin web initial shape curvature upon the member stress state in the crack prone areas, VIII. International Conference on Computational Plasticity (COMPLASVIII), Barcelona 2005.

35. Kala Z. and Kala J., Resistance of Thin-walled Plate Girders under Combined Bending and Shear. WSEAS Transactions on Applied and Theoretical Mechanics 2009. 
36. Kala Z. and Kala J., Sensitivity analysis of lateral buckling stability problems of hot-rolled steel beams, Slovak Journal of Civil Engineering. 2005/2, P.9-14.

37. Kala, Z.; Melcher, J. and Puklický, L., Material and geometrical characteristics of structural steels based on statistical analysis of metallurgical products, Journal of Civil Engineering and Management 15(3): 299-307. doi:10.3846/1392-3730.2009.15.299-307. 2009.

38. Kečman D., Bending collapse of rectangular and square section tubes. Int. J.Mech.Sci., Vol.25, No9-10. 1983.

39. Kotełko M., Rhodes J., and Kim T.H., Post-failure behaviour of box-section beams under pure bending (an experimental study), Thin-walled Structures Vol. 38, pp.179-194. 2000.

40. Królak M. (editor): Post-buckling and load-cpacity of thin-walled girders of flat walls (in Polish: Stany Zakrytyczne i Nośność Graniczna Cienkościennych Dźwigarów o Ścianach Płaskich, PWN, Warszawa-Łódź, Poland. 1990.

41. Kołakowski Z. and Kotełko M., Postbuckling and collapse behaviour of thinwalled beam-columns: International Conference on Lightweight Structures in Civil Engineering, Warszawa. 384-387. 1995.

42. Kotełko M., Failure mechanisms of thin-walled girders under bending with isoand orthotropic walls (in Polish), Scientific Bulletin of Lodz University of Technology, 844, ser. Transactions, 273, Politechnika Łódzka, Łódź. 2000.

43. Website of Department of Strength of Materials, Łódź University of Technology: www.kwm.p.lodz.pl.

44. Lis, P., Kotełko, M. and Kołakowski, Z. 2011. Load-capacity stochastic sensitivity analysis of thin-walled box-section beam, Lightweight Structures in Civil Engineering. Contemporary problems. XVII International Seminar of IASS Polish Chapter (LCCE 2011) Ed. by M. Kamiński and J.B. Obrębski, pp. 120-125, Łódź, Poland.

45. Melcher J. (et al.). 2009. Sensitivity and statistical analysis within elaboration of steel plated girder resistance, International Journal of Advanced Steel Construction, Vol. 5, No 2, pp. 120-126.

46. Minitab Inc., Minitab User's Guide 2: Data Analysis and Quality Tools, Release 13, Minitab Inc; 2000. 
47. Kleiber M. and Hien T. D., The Stochastic Finite Element Method. Chichester: John Wiley \& Sons 1992. 


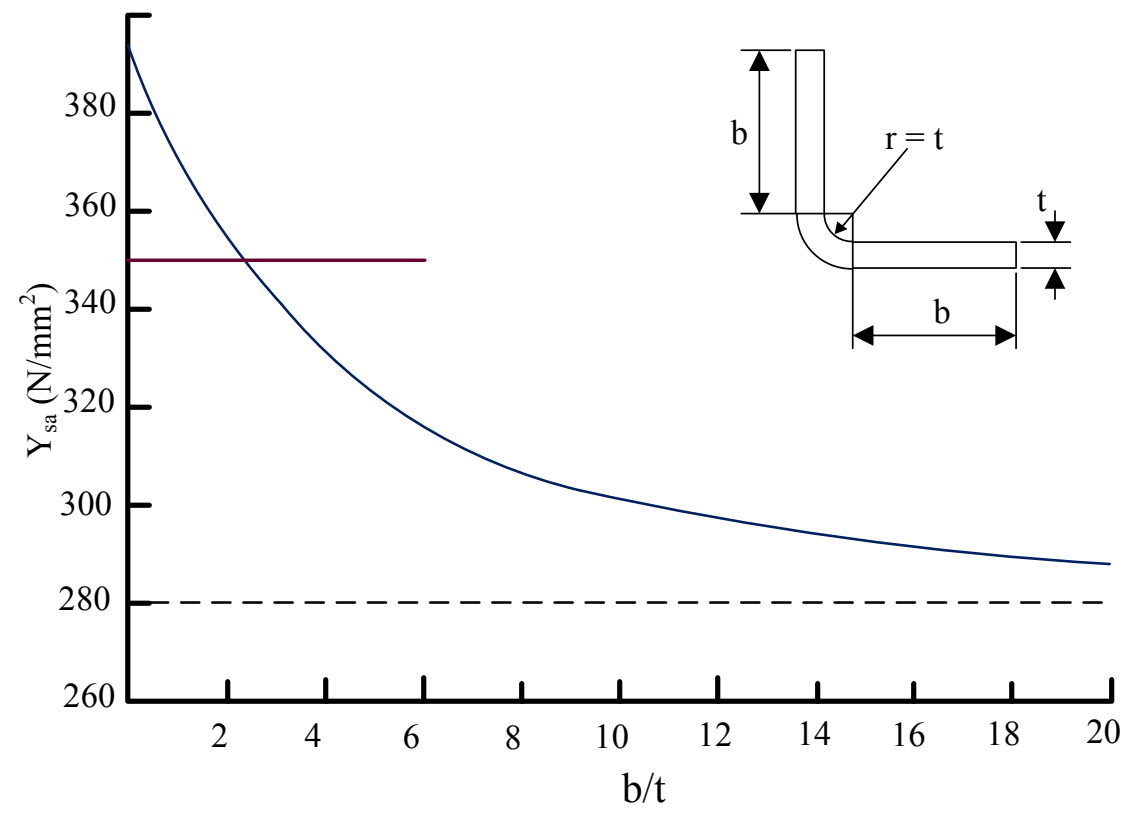

Maximum allowed value

- - - - - - Virgin yield stress

Figure 1

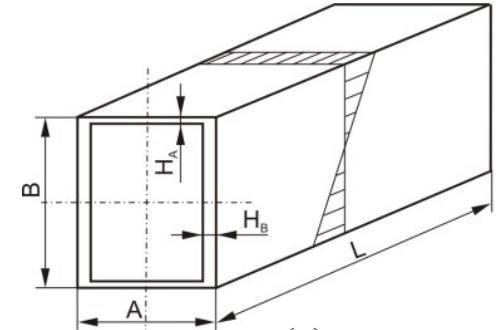

(a)

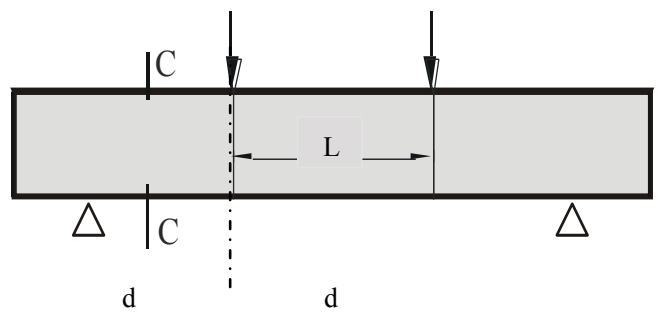

(b)

Figure 2 


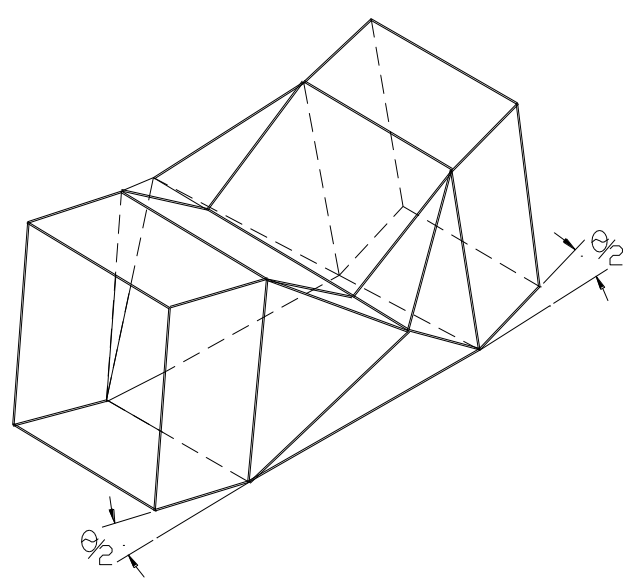

(a)
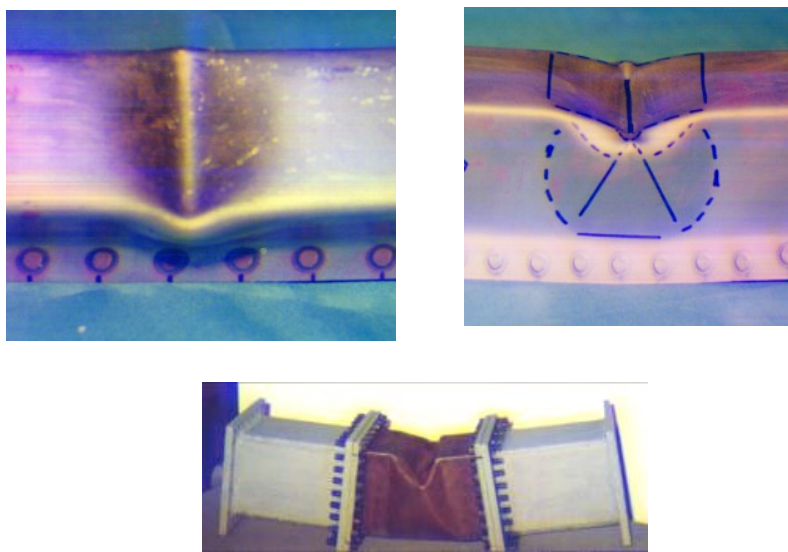

(b)

Figure 3

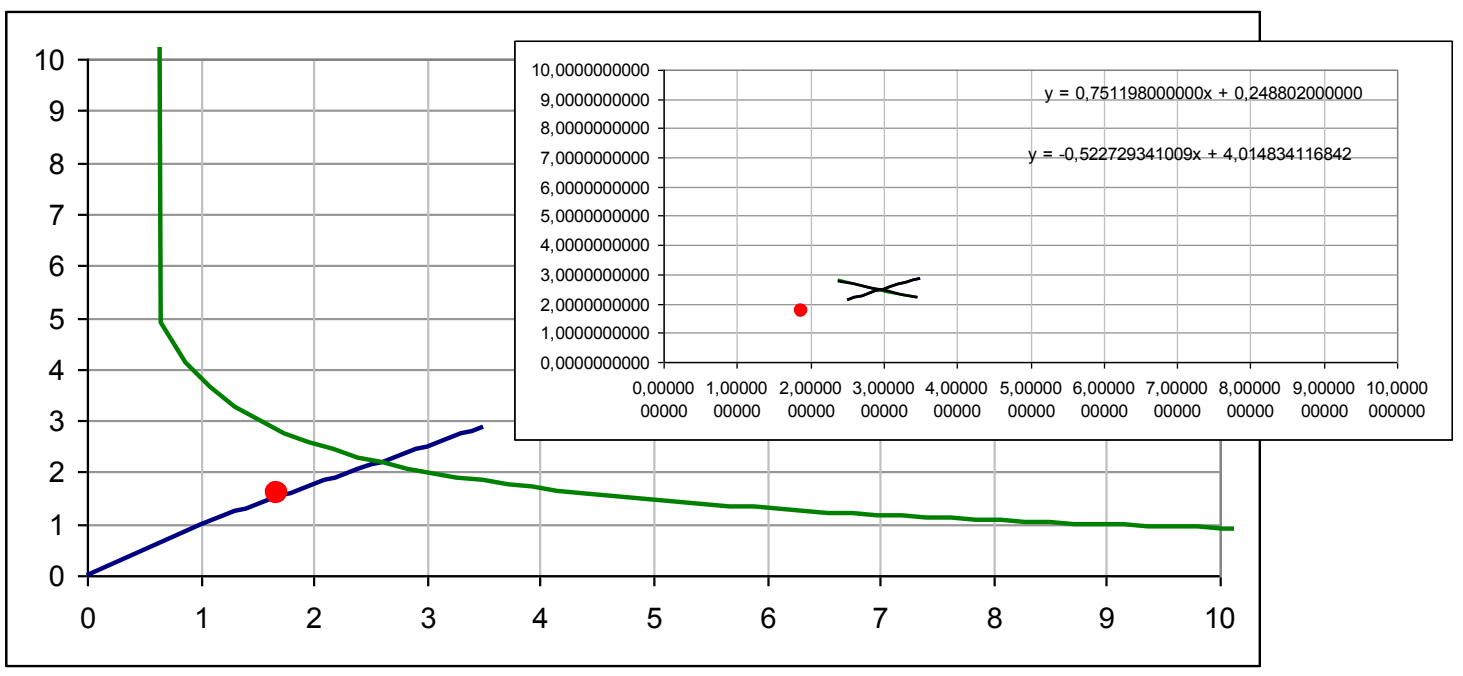

Figure 4 


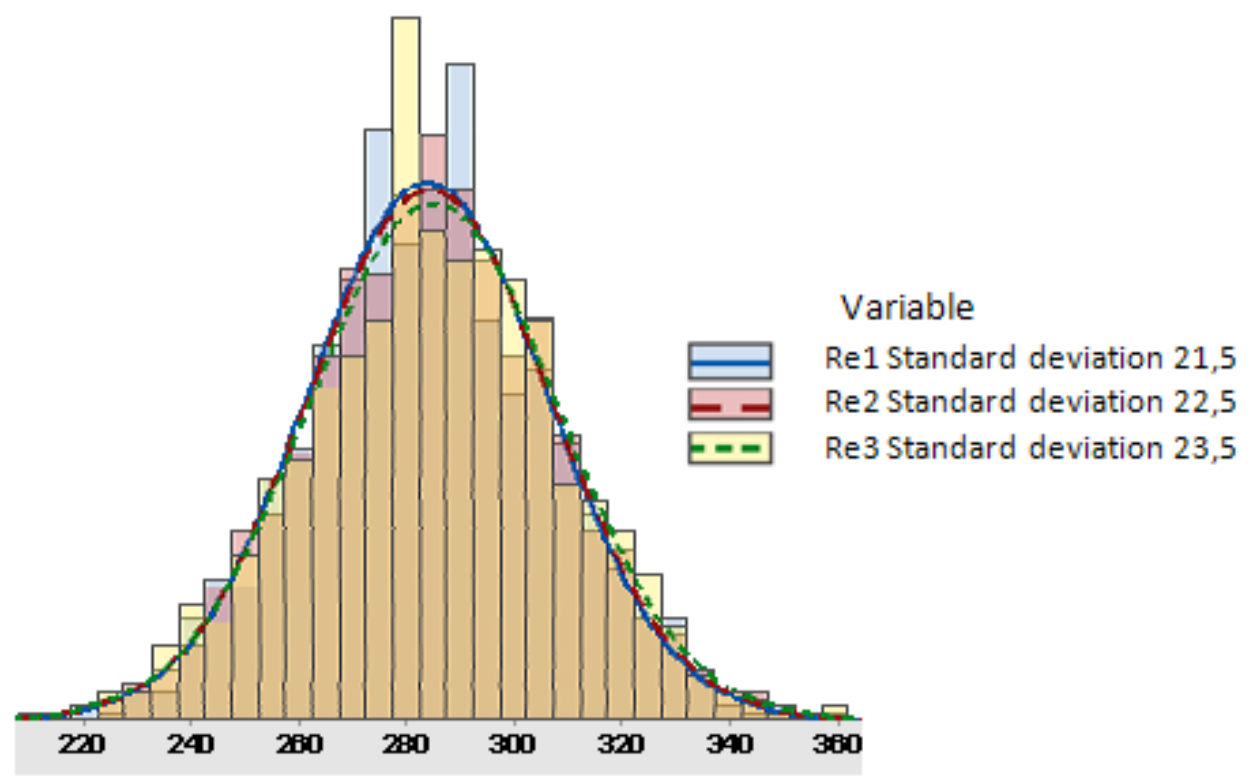

Figure 5

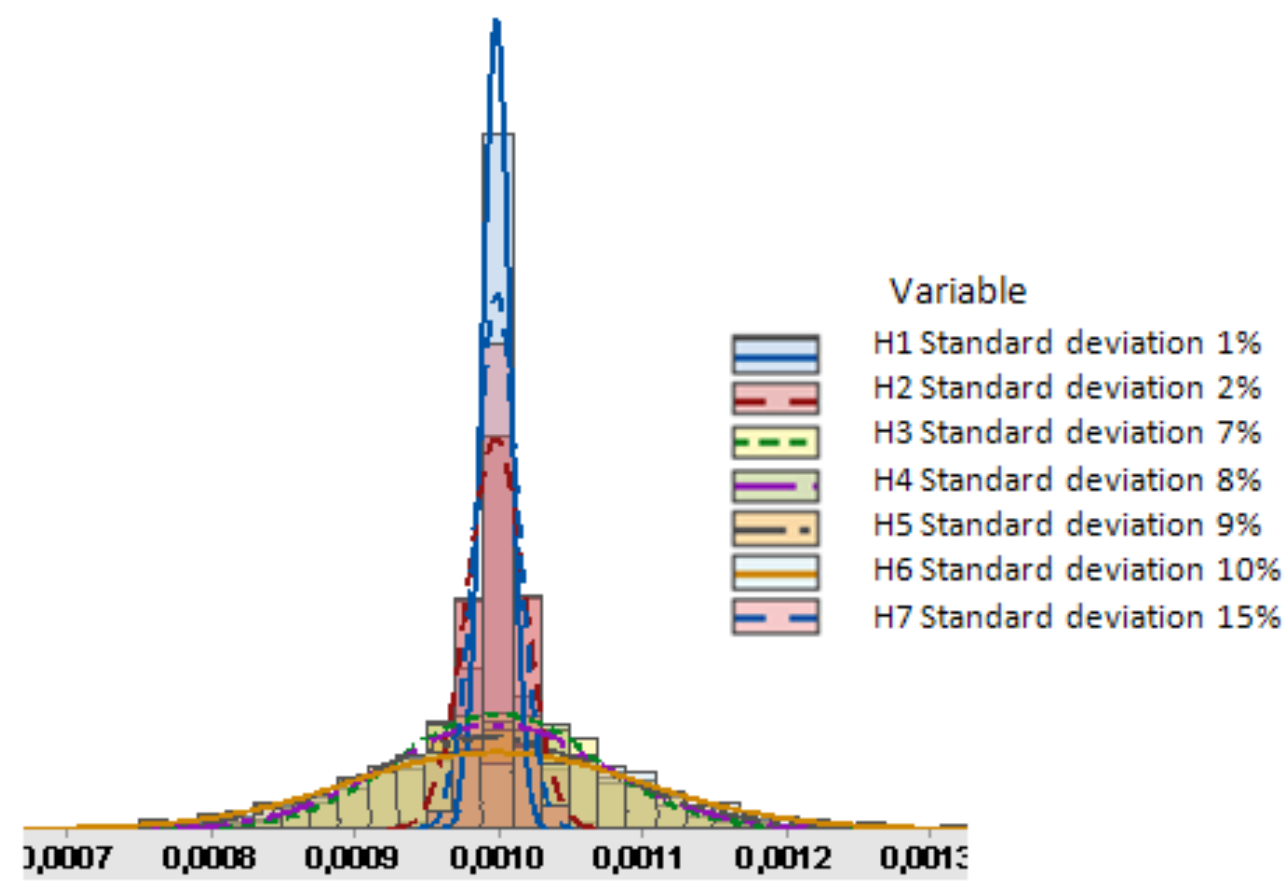

Figure 6 


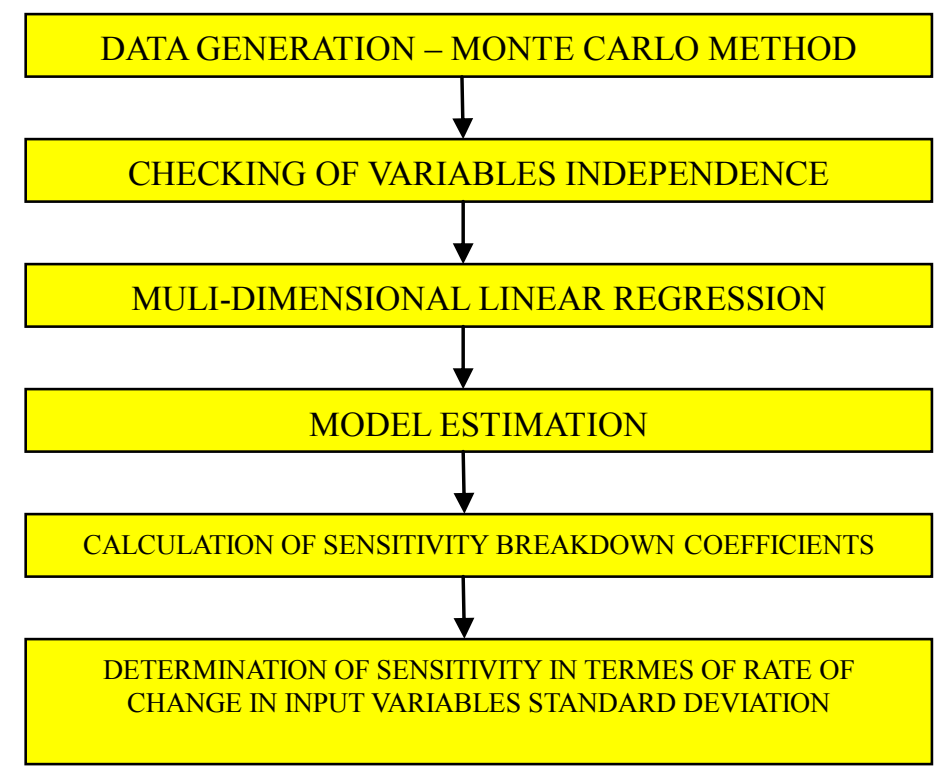

Figure 7 


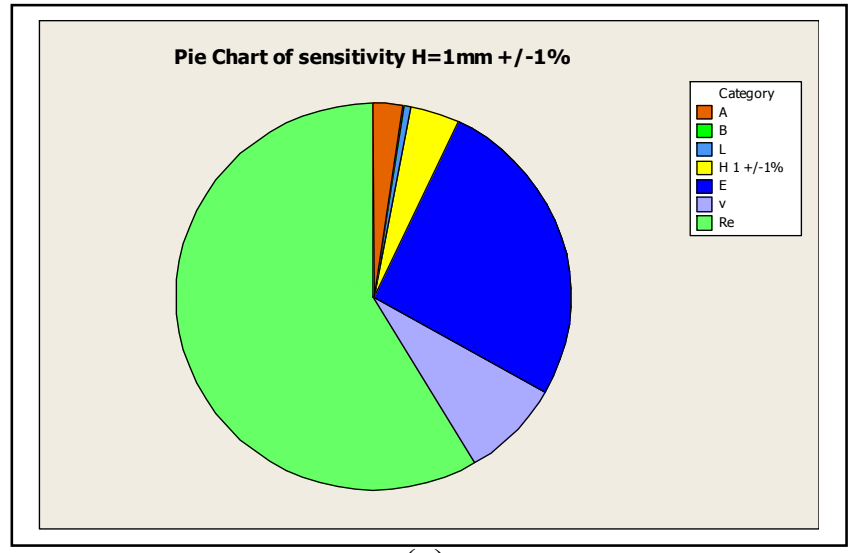

(a)

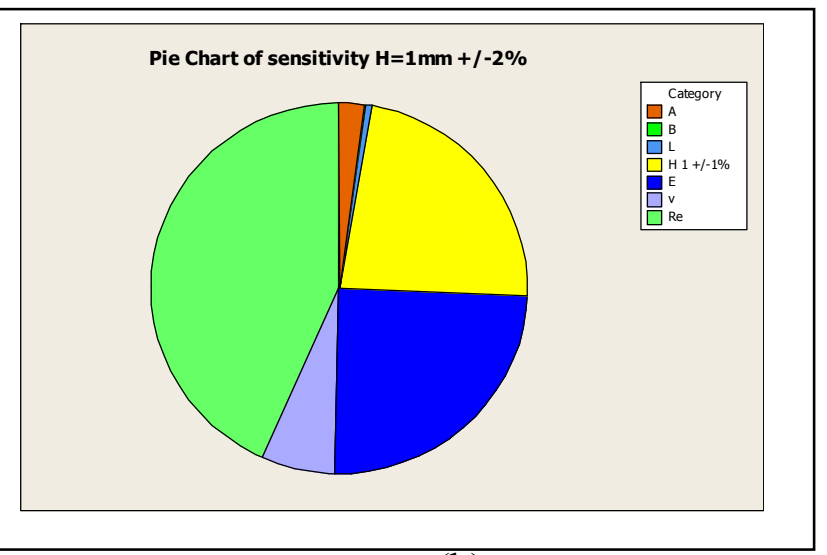

(b)

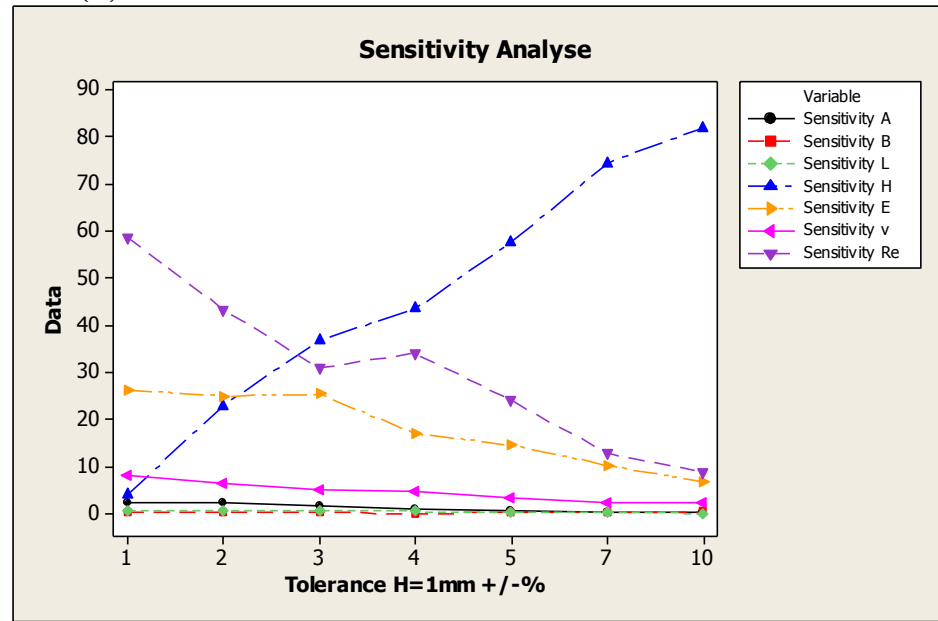

(c)

Figure 8 


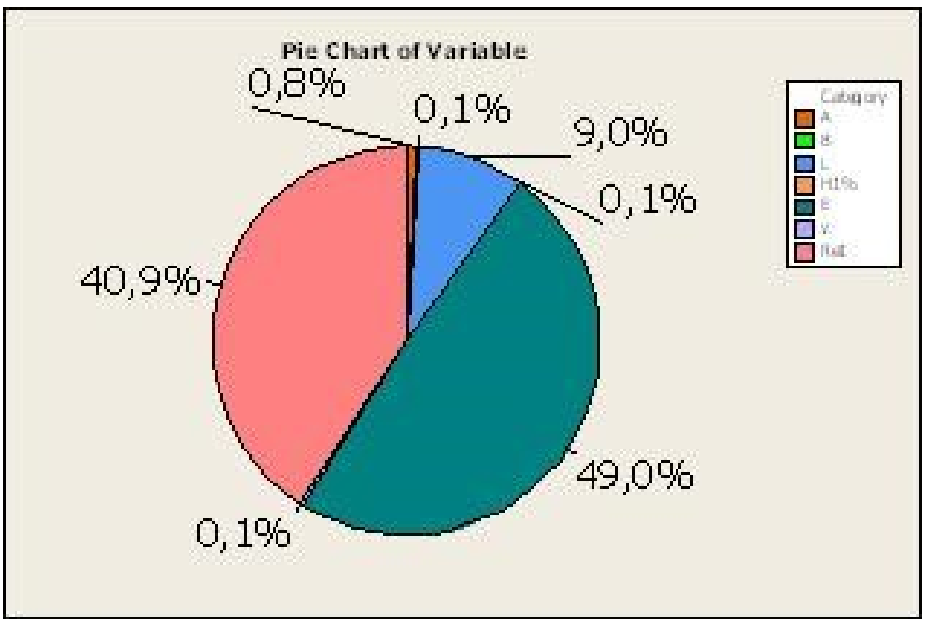

(a)

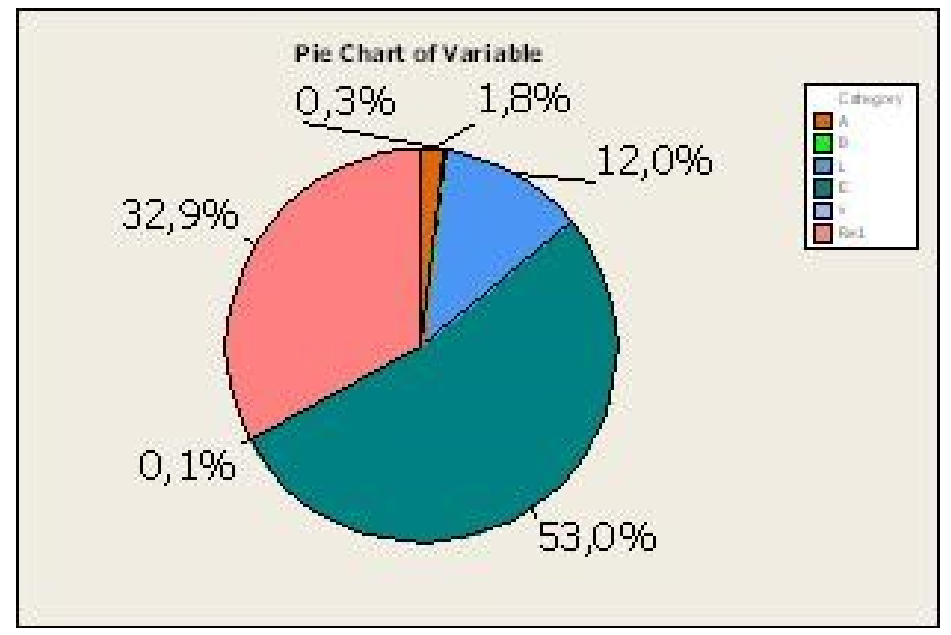

(b)

Figure 9 


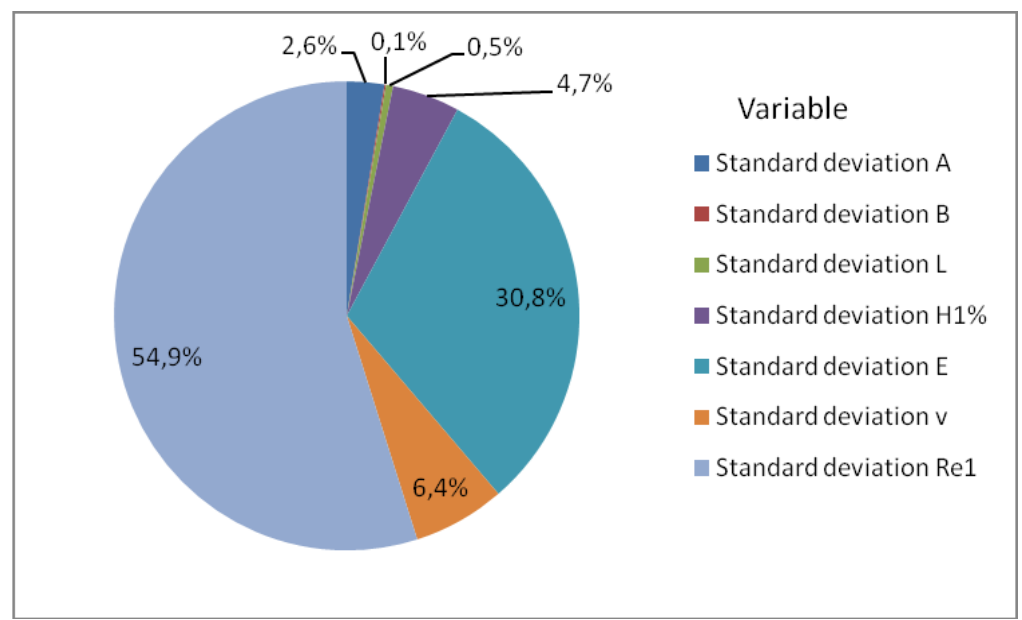

(a)

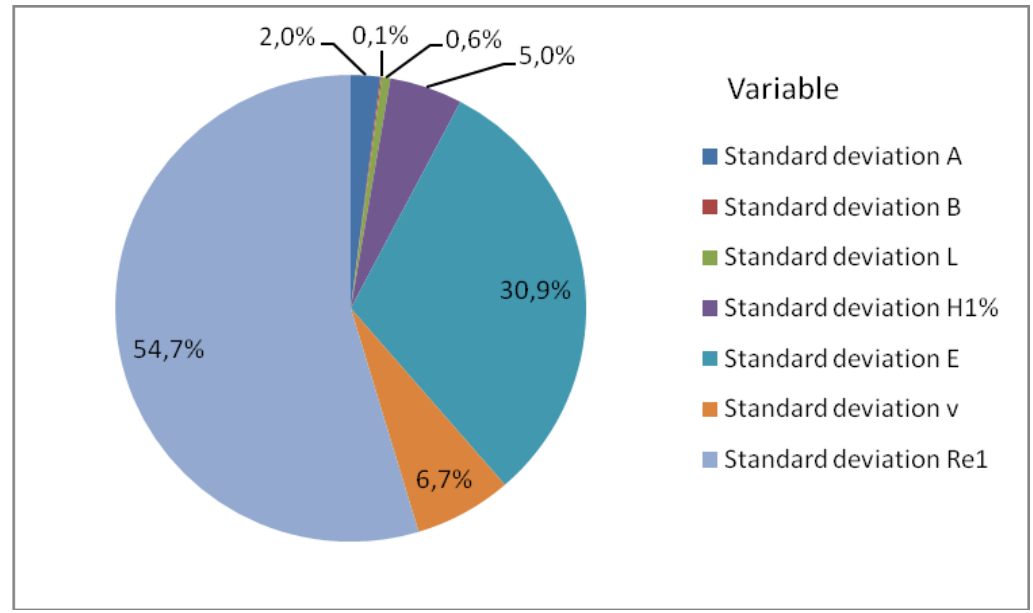

(b)

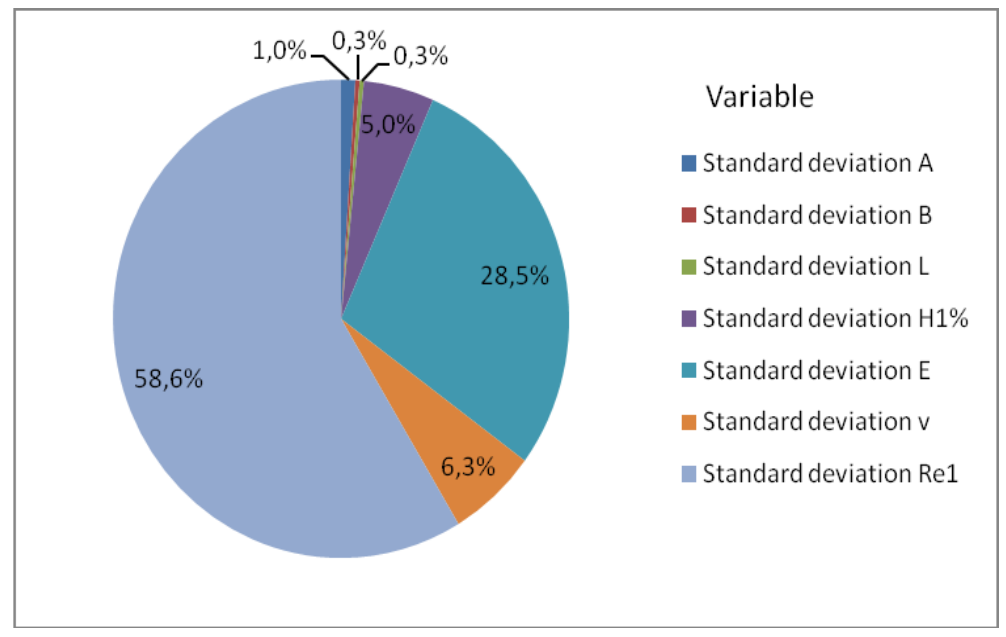

(c)

Figure 10 


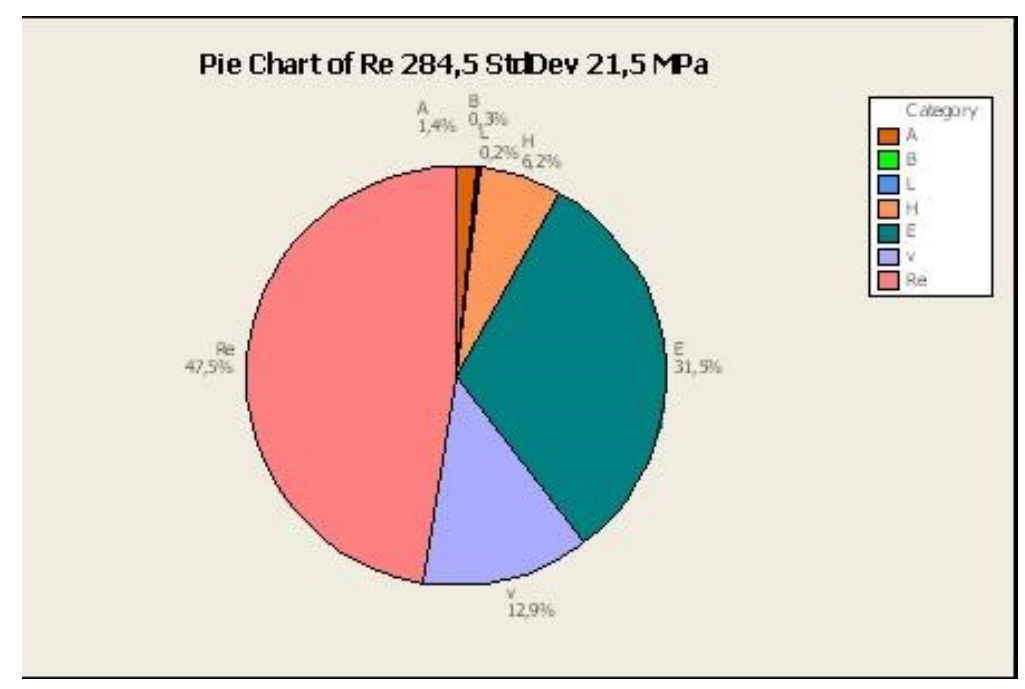

(a)

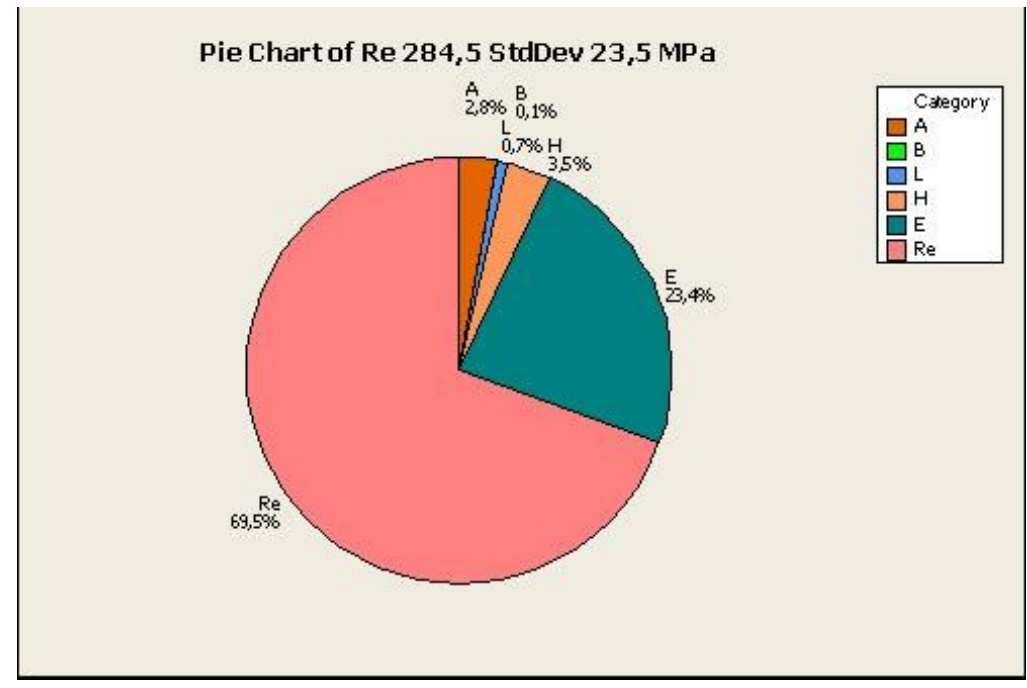

(b)

Figure 11 


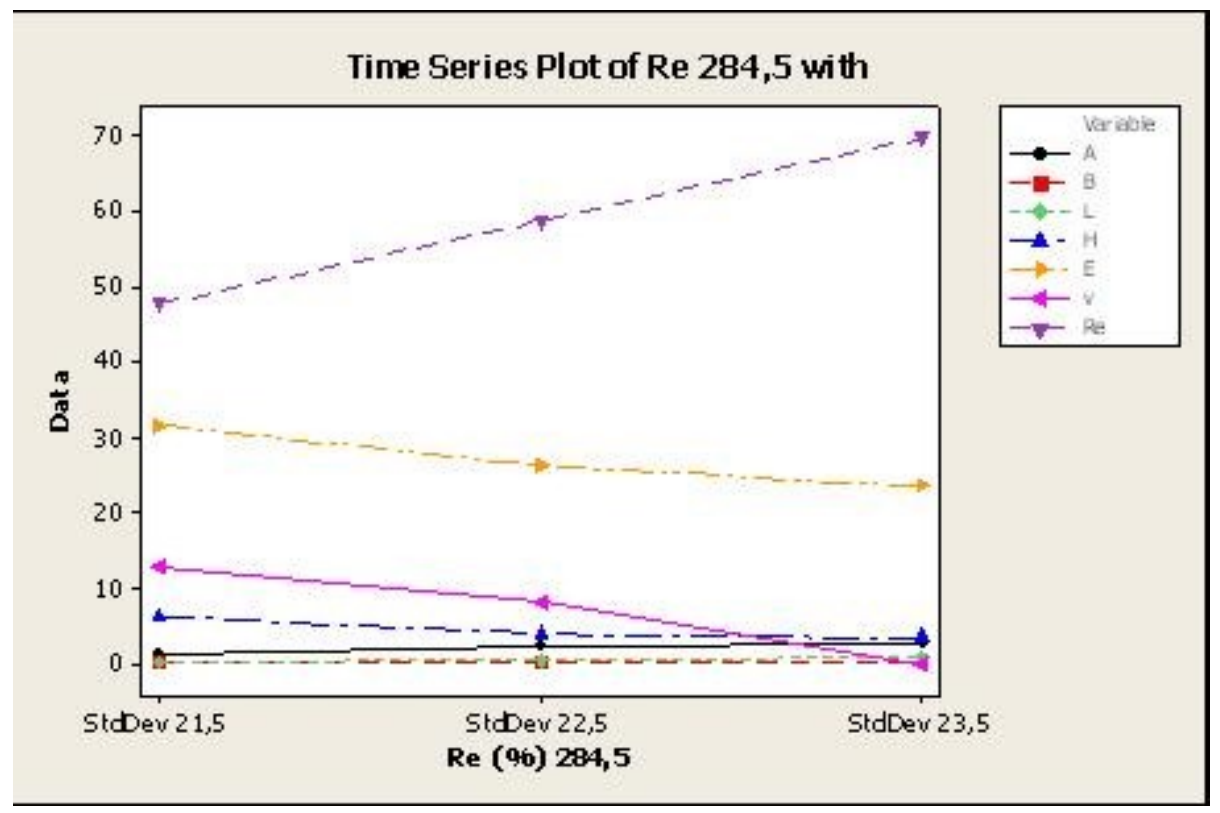

Figure 12

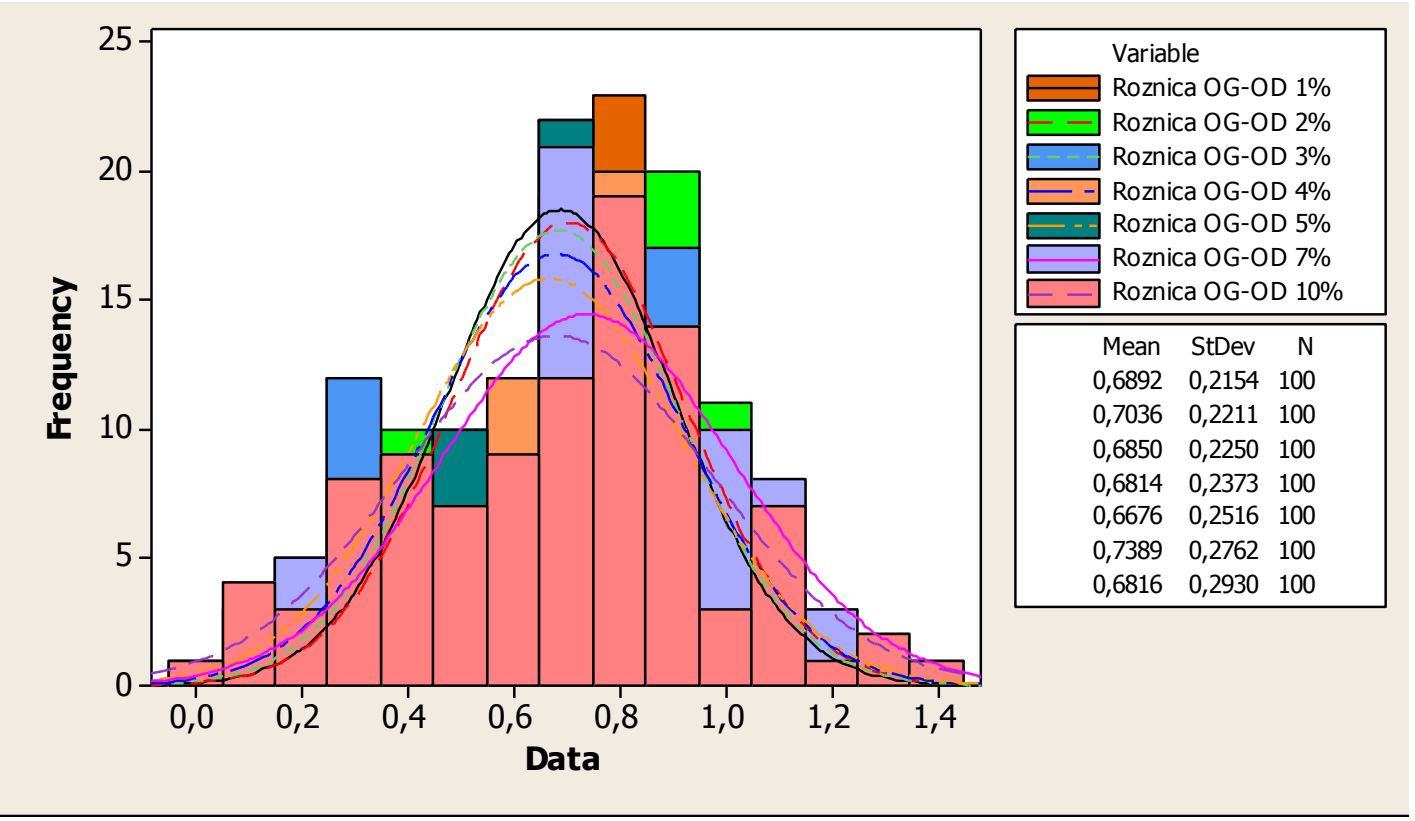

Figure 13 


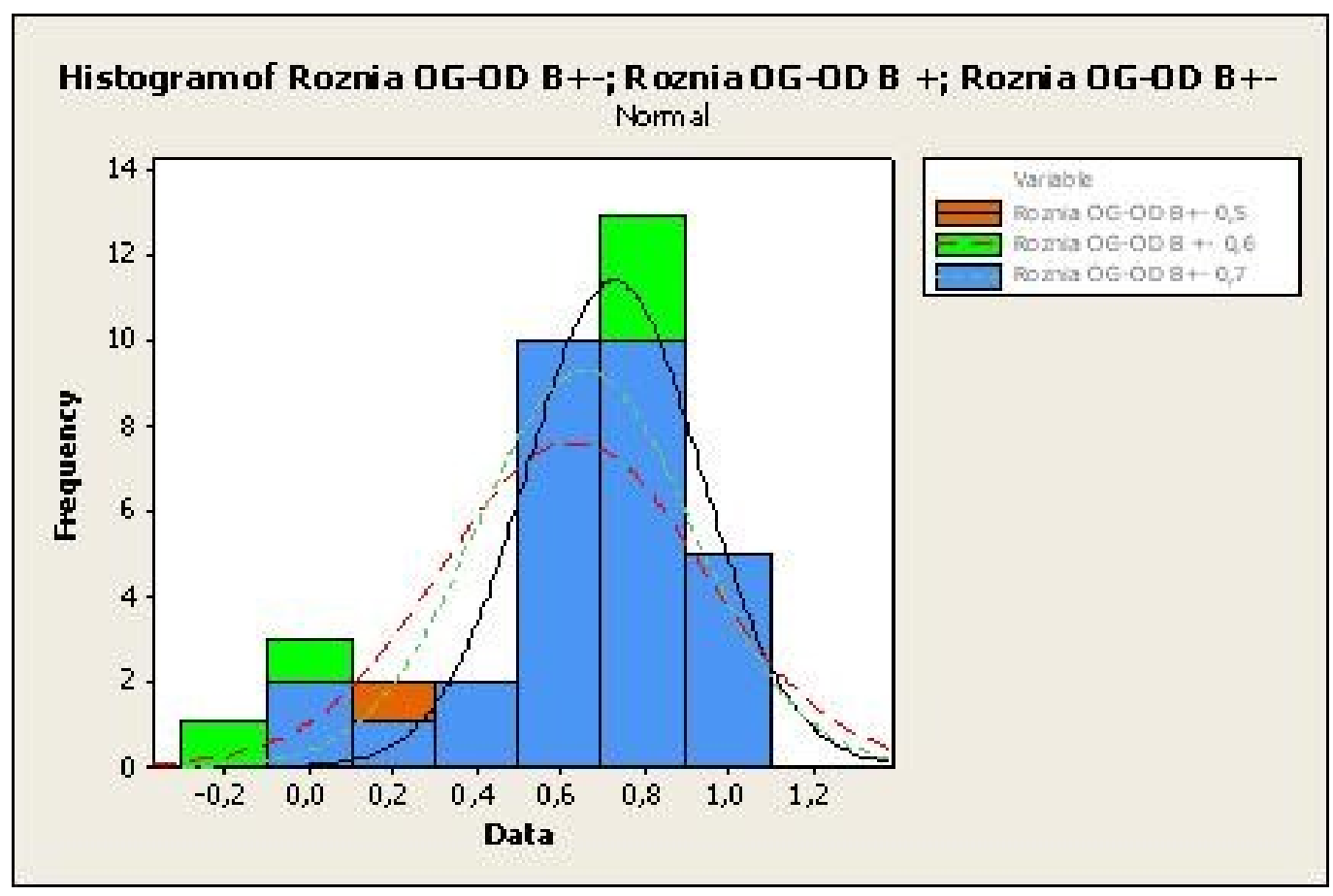

Figure 14

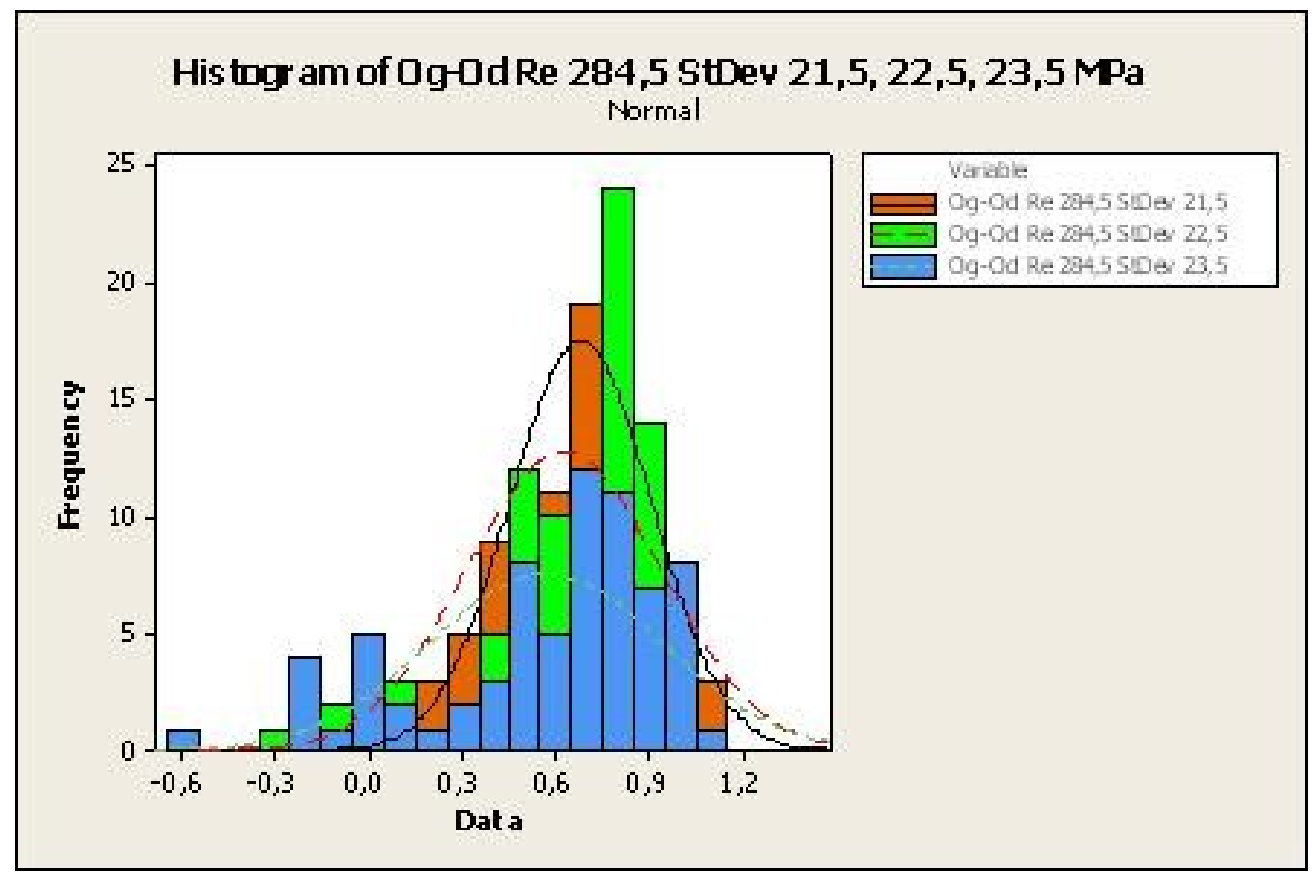

Figure 15 
Table 1

\begin{tabular}{|c|c|c|c|c|}
\hline Random variable & unit & $\begin{array}{l}\text { Mean } \\
\text { value }\end{array}$ & $\begin{array}{l}\text { Standard } \\
\text { deviation }\end{array}$ & $\begin{array}{c}\text { Type of } \\
\text { distribution }\end{array}$ \\
\hline $\begin{array}{l}\text { Width } A \\
\text { Height } B\end{array}$ & $\begin{array}{l}\mathrm{m} \\
\mathrm{m}\end{array}$ & $\begin{array}{l}0.1 \\
0.1\end{array}$ & $\begin{array}{c}0.0005 \\
0.0006 \\
0.0007\end{array}$ & $\begin{array}{l}\text { Norm. (Gauss) } \\
\text { Norm. (Gauss) }\end{array}$ \\
\hline Length $L^{(*)}$ & $\mathrm{m}$ & 0.1 & $\begin{array}{l}0.0005 \\
0.0006, \\
0.0007\end{array}$ & Norm.(Gauss) \\
\hline $\begin{array}{l}\text { Wall thickness } H \\
\qquad\left(H_{\mathrm{A}}=H_{\mathrm{B}}\right)\end{array}$ & $\mathrm{m}$ & 0.001 & $\begin{array}{c}1,2,7, \\
8,9, \\
10,15 \\
{[\%]}\end{array}$ & $\begin{array}{l}\text { Norm. } \\
\text { (Gauss) }\end{array}$ \\
\hline $\begin{array}{l}\text { Young's } \\
\text { modulus E }\end{array}$ & $\mathrm{GPa}$ & 210 & 12.6 & $\begin{array}{l}\text { Norm. } \\
\text { (Gauss) }\end{array}$ \\
\hline $\begin{array}{c}\text { Poisson's ratio } \\
v\end{array}$ & - & 0.27 & 0.03 & $\begin{array}{l}\text { Norm. } \\
\text { (Gauss) }\end{array}$ \\
\hline Yield stress $R_{\mathrm{e}}$ & $\mathrm{MPa}$ & 284.5 & $\begin{array}{l}21.5 \\
22,5 \\
23,5\end{array}$ & $\begin{array}{l}\text { Norm. } \\
\text { (Gauss) }\end{array}$ \\
\hline
\end{tabular}

Table 2

\begin{tabular}{|c|c|c|c|c|}
\hline Test & $\begin{array}{c}\text { Wall thickness } \\
\text { H }\end{array}$ & $\begin{array}{c}\text { Yield stress } \\
\mathrm{R}_{\mathrm{e}}\end{array}$ & $\begin{array}{c}\text { Beam length } \\
\mathrm{L}\end{array}$ & $\begin{array}{c}\text { Beam height } \\
\text { B }\end{array}$ \\
\hline $\begin{array}{l}\text { Lower bound } \\
\text { L-C-E (OD) }\end{array}$ & - & + & - & - \\
\hline $\begin{array}{l}\text { upper-bound L- } \\
\text { C-E (OG) }\end{array}$ & + & - & - & - \\
\hline $\begin{array}{l}\text { Difference } \\
\text { OG-OD }\end{array}$ & - & $+/-$ & - & - \\
\hline OD vs OG & + & + & + & + \\
\hline
\end{tabular}


Captions of figures and tables:

Figure 1: Variation in predicted average yield strength for a cold-formed bend with variation in geometry ([2]).

Figure 2: Box-section girder under pure bending: (a) dimensions; (b) load and support lay-out.

Figure 3: Plastic mechanism of failure in box-section beam under pure bending: (a) theoretical model [6]; (b) experiment [39,42].

Figure 4: Exemplary chart of program 'NOSNOSC'

Figure 5: Histogram of the yield stress distribution [30]

Figure 6: Histogram of wall thickness distribution

Figure 7: Sensitivity analysis algorithm.

Figure 8: Sample pie charts OG sensitivity analysis - wall thickness variance: (a) $1 \%$ standard deviation; (b) $2 \%$ standard deviation; c) diagram of breakdown coefficients.

Figure 9: Pie chart of OG sensitivity analysis in terms of beam height variance: SD 0.5 ; (b) SD. $0.6[\mathrm{~mm}]$.

Figure 10: Pie chart of OG sensitivity analysis in terms of distance L variance: (a) SD 0.5 ; (b) SD 0.6; (c) SD $0.7[\mathrm{~mm}]$.

Figure 11: Sample pie charts (OG sensitivity analysis - yield stress variance): (a) 21.5 MPa SD, (b) 23.5 MPa SD.

Figure 12: Results of OG sensitivity analysis - yield stress variance.

Figure 13: Sample histogram - upper-bound (OG) and lower-bound (OD) differences for wall thickness variance.

Figure 14: Sample histogram - upper-bound (OG) and lower-bound (OD) differences for beam height variance. 
Figure 15: Sample histogram - upper-bound (OG) and lower-bound (OD) differences for the yield stress variance.

Table 1: Input random variables

Table 2: Summary of ANOVA tests results 